\title{
Comprehending illocutionary force
}

\author{
THOMAS HOLTGRAVES and AARON ASHLEY \\ Ball State University, Muncie, Indiana
}

\begin{abstract}
According to speech act theory (Searle, 1969), utterances have both a propositional content and an illocutionary force (the speech act performed with the utterance). Four experiments were conducted to examine whether utterance comprehension involves speech act recognition. Participants in all experiments first read remarks that could be characterized by a particular speech act (e.g., beg). A recognition probe reaction time procedure was used in Experiments 1 and 2; participants indicated whether a probe word had literally appeared in the last remark that they had read. Participants were significantly slower at making this judgment (and made significantly more errors) when the probe represented the speech act performed with the prior remark than when it did not. A lexical decision task was used in Experiments 3 and 4, and participants were significantly faster at verifying target words representing the speech act performed with a remark, relative to control words. Overall, the results suggest that speech act recognition may be an important component of the comprehension of conversational remarks.
\end{abstract}

Language use is a form of social action. When people speak, they are usually attempting to do something with their words; they are complimenting, complaining, criticizing, and so on. But the link between language and action is not always clear. The same action (e.g., a request) can be performed in many different ways, and the same utterance can, depending on the context, perform many different actions. Moreover, it is not clear whether comprehension even involves recognition of the action that is performed with an utterance. That is, when we comprehend a speaker's remark, does that comprehension involve recognition, at some level, of the action that the speaker is undertaking? Does comprehension of "Don't forget to stop at the store" involve recognition that the speaker is performing the act of reminding? Surprisingly, with the exception of research on recognition of indirect speech acts (e.g., Gibbs, 1983), very little empirical research has addressed this issue. The purpose of this research was to undertake some initial analyses of the extent to which comprehension involves recognition of the action-or speech act - that is performed with an utterance.

The view of language as social action is most clearly captured in speech act theory (Austin, 1962; Searle, 1969; Searle \& Vanderveken, 1985). Fundamental to this approach is the concept that language use involves the simultaneous performance of multiple acts. At one level, a speaker is performing a locutionary act, or producing a sentence with a particular sense and reference (roughly, its propositional meaning). Simultaneously, a speaker is

This research was supported by a grant from the National Science Foundation (SBR 9601311) awarded to the first author. Experiment 1 was reported at the 1998 annual meeting of the American Psychological Society, Washington, DC. Correspondence regarding this manuscript should be addressed to T. Holtgraves, Department of Psychological Science, Ball State University, Muncie, IN 47306 (e-mail: 00t0holtgrav@bsu.edu). performing an illocutionary act, or act in saying. The term illocutionaryact refers to the specific force associated with the uttering of particular words in a particular context; it is the specific speech act (e.g., warn, request, promise, etc.) that a speaker performs. This view has clear implications for models of language comprehension, because it suggests that the comprehension of an utterance will involve recognition of both the propositional meaning and the act performed with the remark.

Although the illocutionary act places some restrictions on propositional meaning (e.g., one cannot request another to perform some act in the past), it is possible for utterances to have the same propositional meaning but perform different speech acts. Consider the following utterances:

(1) I predict you will come to my party.

(2) Will you come to my party?

(3) Please come to my party.

The propositional meaning (that the addressee will attend the speaker's party) is the same for all three utterances. Yet, in most contexts the first has the force of a prediction, the second a question, and the third a request.

How is it that addressees recognize the specific speech acts performed with these utterances? Sometimes an utterance will contain a performative verb, a verb that names the speech act performed. For example, in (1) the verb predict names the specific speech act that is performed with the utterance. But many times an explicit performative is not part of the utterance, in which case the speech act performed is named with an implicit verb (a verb that is not literally in the remark). For example, in most contexts (3) performs the speech act of requesting, and the performative verb (request) is implicit. How is it that addressees will recognize that it is a request that is being performed with this remark? In general, speech act theorists have suggested that sentence type and mood, intonation, back- 
ground knowledge, and other relevant features of the context come into play and aid the addressee's recognition of the speech act performed (Austin, 1962; Searle, 1969). But a more fundamental question needs to be addressed. Specifically, is it the case that addressees actually recognize the performance of a specific speech act? When Andy says to Bob "I'll definitely do it tomorrow," does Bob's representation of Andy's utterance include the illocutionary force of the remark (that it is a promise)? Note, in this regard, that there are alternatives to speech act theory for which illocutionary force recognition is not required (see, e.g., Cohen \& Levesque, 1990).

Although activation of illocutionary force has not yet been investigated, Schweller, Brewer, and Dahl (1976) have demonstrated that readers often misremember speech act verbs (e.g., ask) as having been present in sentences (e.g., The cute little girl told her mother she wanted a drink) that they have read earlier. This suggests that illocutionary force at some level and at some point in time is playing a role in the comprehension and representation of these sentences. More recently, Amrhein (1992) has shown that the comprehension of certain speech acts (e.g., promise) involves recognition of the components underlying illocutionary force. For example, the comprehension of promise entails recognition of the speaker's desire and ability to perform a particular act; hope entails recognition of the speaker's desire but not his or her ability to perform the particular act; and so on. In Amrhein's research, the critical sentences contain explicit performative verbs (e.g., promise, hope, etc.); whether implicit performative verbs are activated at comprehension has not been demonstrated. Moreover, other researchers have reported evidence that some explicit performative verbs such as to promise do not require the meeting of felicity conditions in order to be validly used (Gibbs \& Delaney, 1987).

Recognition of the illocutionary force of implicit performatives represents an inference process of sorts; the speech act verb is not literally present in the sentence and must be inferred. Although this issue has not been examined directly, research on the comprehension of texts does support this notion. For example, much research on text processing has been directed toward uncovering the extent to which text comprehension involves inferential processing (e.g., Graesser, Singer, \& Trabasso, 1994; McKoon \& Ratcliff, 1992). According to a constructionist model (Graesser et al., 1994), readers make inferences that are necessary for maintaining local coherence, and these include referential (Dell, McKoon, \& Ratcliff, 1983), causal antecedent (Singer, Halldorson, Lear, \& Andrusiak, 1992), and case role assignment inferences (Swinney \& Osterhout, 1990). These inferences appear to be generated automatically (i.e., on line) during comprehension (see also McKoon \& Ratcliff, 1992).

But additional inferences may also be made on line (depending on the type of text and the reader's processing goal). Specifically, inferences regarding superordinate goals (Dopkins, Klin, \& Myers, 1993) and charac- ters' emotional reactions (Gernsbacher, Goldsmith, \& Robertson, 1992) appear to be made under certain conditions. These inferences are made as a means of explaining why various actions have occurred in the text, as a result of a general search after meaning (Graesser et al., 1994). In a similar manner, illocutionary force can be viewed as representing the "why" behind a particular remark; the remark is being uttered in order to perform a particular act. Thus Bill says "I'll definitely do it tomorrow" to Bob in order to perform a promise. Hence, Bob's representation of Bill's remark may include the inference that his utterance constitutes a promise.

Finally, the research of Uleman (1987) and others on spontaneous trait inferences also supports the possibility of illocutionary force activation. Spontaneous trait inferences are dispositional inferences made about a person that occur when one is comprehending a description of that person's behavior. For example, the sentence The librarian carries the old women's groceries across the street implies that the librarian is "helpful," and comprehension of this sentence appears to involve an activation of the trait helpful. Using a variety of methods, including recognition probe reaction times (Uleman, Han, Roman, \& Moskowitz, 1996), cued recall (Winter \& Uleman, 1984; Winter, Uleman, \& Cunniff, 1985), and implicit memory (Whitney \& Williams-Whitney, 1990), researchers have documented the on-line activation of trait inferences. Although there has been some debate about whether or not these inferences are truly spontaneous (i.e., automatic) (Bassili \& Smith, 1986; Higgins \& Bargh, 1987), it is clear that under many conditions such inferences will be made during comprehension. Just as trait inferences represent the categorization of a verbal description, speech act recognition involves the assigning of an utterance to a particular speech act category. If comprehension of behavior descriptions entails the activation of trait inferences, it seems reasonable that speech act recognition should accompany the comprehension of certain conversation remarks.

In the present research, we used a recognition probe reaction time procedure (Experiments 1 and 2) and a lexical decision task (Experiments 3 and 4) to investigate whether or not illocutionary force is activated during comprehension. The speech acts used in these studies were chosen from the list of illocutionary verbs developed by Searle and Vanderveken (1985) and represented four of these authors' five illocutionary points: expressives (apologize, thank), assertives (brag, agree, accuse, remind, blame), directives (warn, beg, encourage), and commissives (threaten, invite).

\section{EXPERIMENT 1}

Participants read scenarios that were followed by a short conversational exchange (see Table 1). On critical trials, the final remark of the exchange either performed a specific speech act (e.g., remind as in Table 1) or did not perform this particular speech act. After having read 
Table 1

\section{Sample Scenario and Speech Act Manipulation}

Jenny and Emily had been close friends since grade school. Now they were rooming together at college.

Emily was very forgetful.

Today, Jenny was sure Emily didn't remember (had forgotten) her dentist appointment.

Jenny: Don't forget (I'll bet you forgot) to go to your dentist appointment today.

Probe: remind

Note-The speech act version contained the italicized material; the control version was created by replacing the italicized material with the material in parentheses.

the final remark, the participants were asked to indicate whether or not a probe word (e.g., remind) had literally appeared in the last remark that they had read. If comprehension of a remark involves activation of its illocutionary force, then, when the probe represents the speech act just performed, participants' ability to verify that the probe had not been literally present should be slowed; activation of the speech act term should interfere with performance on this task. For example, participants should be slower at verifying that the word remind had not literally been present in the remark Don't forgot to go to your dentist appointment today relative to a control remark I'll bet you forgot to go to your dentist appointment today. On the basis of speech act theory and the empirical research cited above, we expected reaction times to be slowed, and errors to be increased, when the probe word characterized the speech act performed with the final remark than when it did not.

\section{Method}

Participants. Participants $(N=55)$ were students enrolled in introductory psychology classes at Ball State University who participated for partial course credit. All participants were native speakers of English.

Materials. Twelve scenarios and corresponding dialogues were written. The scenarios contained two to five sentences and were followed by either a single remark or a two-remark exchange. Two versions of each scenario/dialogue were written. In the speech act version, the final remark performed a particular speech act (e.g., apologize, brag, agree, etc). In the control version, the last remark did not perform this particular speech act. An example is presented in Table 1.1

The speech act remarks were chosen on the basis of a pretest in which a group of participants $(N=36)$ was asked to read a scenario/ dialogue and then provide a single word that described what the speaker of the last remark was doing with the remark. For the speech act sentences, an average of $75 \%$ of the pretest participants provided the expected speech act term.

Two sets of the materials were created, with each set containing six speech act scenarios and six control scenarios. The two sets were mirror images of each other; if the control version of a scenario appeared in one set, the speech act version appeared in the other set. In this way each participant saw equal numbers (six) of speech act and control scenario/dialogues, and across the experiment equal numbers of participants saw the control and speech act versions of each scenario/dialogue.

For the 12 critical trials the probe word had not literally been in the final remark. In order to prevent participants from developing an expectation that the probe word was never included in the final remark, 12 filler trials were included. The format of these trials was identical to that of the critical trials, except that the probe word always appeared in the last remark. The presentation order of the materials was randomized for each participant.

Procedure. The experiment was conducted on a personal computer using the Micro Experimental Laboratory software package (MEL, Version 2). The participants first read detailed instructions regarding the task and then engaged in four practice trials. The experimenter provided feedback during the practice trials.

The participants pushed the Enter key to begin a trial. The first sentence of the scenario appeared on the screen. The participants read the materials at their own pace, pushing the Enter key to proceed through the material. After indicating comprehension of the last remark, the screen went blank for $250 \mathrm{msec}$, a $500-\mathrm{Hz}$ tone sounded for $50 \mathrm{msec}$, and the probe then appeared in the middle of the screen. The participants were instructed to indicate, as quickly as possible, whether or not the probe had literally been in the last remark they had read. They pushed the key marked YES (/ key) if it had been in the previous remark, and the key marked NO (z key) if it had not been in the previous remark. For the 12 critical trials, the probe was always the speech act term and so the correct answer (for both the control and speech act versions) was NO. For the 12 filler trials, the correct answer was always YES. Immediately after making a judgment, feedback (correct /incorrect and response time) was presented on the computer screen for $1,750 \mathrm{msec}$. The participants then pushed the Enter key to begin the next trial.

\section{Results and Discussion}

In this and all subsequent experiments, analyses were conducted with both participants $\left(F_{1}\right)$ and stimuli $\left(F_{2}\right)$ as random variables. All reported means, however, were calculated averaging over participants. For the analysis of recognition probe reaction times, only error-free trials were included in the analyses. Unless otherwise noted, all effects described as significant were reliable at least at $p<$ .05 . The results are summarized in Table 2 .

As expected, participants were significantly slower at verifying that the probe had not been literally present when it represented the speech act performed with the final remark $(M=1,037 \mathrm{msec})$ than when it $\operatorname{did} \operatorname{not}(M=$ $960 \mathrm{msec})$. This difference was reliable over participants $\left[F_{1}(1,54)=14.28, M S_{\mathrm{e}}=66,846\right]$, although not over stimuli $\left[F_{2}(1,11)=2.56, M S_{\mathrm{e}}=15,569, p<.15\right] .^{2}$

The overall error rate was $3.9 \%$. However, as expected, the error rate varied as a function of whether or not the probe word characterized the speech act performed with the final remark. When it did, participants were more likely to incorrectly indicate that the probe had been present $(6.36 \%)$, relative to the control versions $(1.52 \%)$. This difference was reliable over participants $\left[F_{1}(1,54)=\right.$ 9.92, $\left.M S_{\mathrm{e}}=.04\right]$ and over stimuli $\left[F_{2}(1,11)=6.90\right.$, $\left.M S_{\mathrm{e}}=.002\right]$.

Table 2

Probe Reaction Times (RT, in Milliseconds) and Error Rates (E): Experiments 1 and 2

\begin{tabular}{cccccc}
\hline & \multicolumn{2}{c}{ Speech Act Sentences } & & \multicolumn{2}{c}{ Control Sentences } \\
\cline { 2 - 3 } Experiment & RT & E & & RT & E \\
\hline 1 & 1,037 & $6.36 \%$ & & 960 & $1.52 \%$ \\
2 & 1,099 & $9.42 \%$ & & 1,047 & $5.44 \%$ \\
\hline
\end{tabular}


Taken together, the results for judgment speed and error rate indicate that comprehenders were recognizing the illocutionary force of these utterances. A potential problem with this experiment is that participants took longer to read the final remark when it performed the relevant speech act $(M=3,118 \mathrm{msec})$ than when it did $\operatorname{not}(M=1,965 \mathrm{msec})\left[F_{1}(1,54)=168, M S_{\mathrm{e}}=1,265,991\right.$; $\left.F_{2}(1,11)=21.8, M S_{\mathrm{e}}=9,657,136\right]$. Hence, slowed judgment speeds following the relevant speech act utterances could have been due to the greater comprehension difficulty for these remarks, relative to the control remarks. In order to eliminate this as a possibility, an additional analysis of covariance was conducted, with reading time for the final remark as a covariate. In this analysis, the main effect of speech act activation on judgment speed remained significant $\left[F_{1}(1,53)=5.09, M S_{\mathrm{e}}=10,475\right]$.

\section{EXPERIMENT 2}

This experiment was an attempt to replicate and extend the results of Experiment 1. The participants performed the same recognition probe reaction time task as before. However, two changes were made in the procedure. First, the final remarks in the control versions of the dialogues were lengthened in order to equate comprehension difficulty for the speech act and control remarks.

Second, a modified recognition memory task was included in the procedure. After completing the reaction time portion of the study, the participants were given a list of 24 words and asked to indicate which of the words characterized remarks that they had read earlier. Twelve of these words were the speech acts examined in this research. Thus, for any participant, 6 of these words represented speech acts that had been performed with remarks they had read earlier; the remaining 6 words did not represent performed speech acts (i.e., they had been paired with the control remarks).

This task served as an off-line measure of illocutionary force activation; it provided an additional means of verifying that the critical remarks had been characterized in terms of the speech acts they performed. If comprehension involved speech act recognition, the participants should display subsequent awareness of the speech acts performed with the remarks that they had read. Accordingly, we expected the participants to be more likely to indicate that the speech act words characterized remarks that they had read earlier, relative to words that had not performed speech acts. Note that the participants saw all 12 of the speech act words (they constituted the presented probes) prior to the administration of this task. However, this was the case for both the 6 words representing performed speech acts and the 6 words that had not performed speech acts. Thus, any difference between the speech act words and the controls would reflect recognition of the illocutionary force of the speech act remarks.

\section{Method}

Participants. The participants $(N=46)$ were students enrolled in introductory psychology classes at Ball State University who participated for partial course credit. All participants were native speakers of English.

Materials. The materials for the reaction time portion of the study were identical to those used in Experiment 1, except that each of the control sentences was lengthened.

The recognition task consisted of a list of 24 words. Twelve of these words were the speech acts performed with the final remarks. For any participant, then, 6 of these words represented speech acts that had been performed with the final remark (the 6 speech act sentences) and six words that had not performed speech acts (the six control sentences). For each of the 12 speech act words, an equal number of participants responded to the word when it represented a performed speech act and when it did not. The 12 remaining words served as fillers and were not associated with the presented sentences.

Procedure. The procedure for the reaction time task was identical to that used in Experiment 1, except that a sentence was inserted in the instructions to the effect that the participants should read the material carefully because later they would be asked some questions about what they had read.

After they had completed the reaction time portion of the experiment, the participants were given the list of recognition test words. For each of these words, the participants were asked to "indicate whether or not it characterizes a remark that you previously read."

\section{Results and Discussion}

Lengthening the control remarks had the desired effect. In contrast to the results of Experiment 1, the control remarks $(M=3,747 \mathrm{msec})$ now took longer to read than the speech act remarks $(M=3,386 \mathrm{msec})\left[F_{1}(1,45)=13.53\right.$, $M S_{\mathrm{e}}=1,299,178 ; F_{2}(1,11)=1.54, M S_{\mathrm{e}}=10,134,957$, $p>.05]$.

The results are summarized in Table 2. As in Experiment 1 , the participants had difficulty correctly rejecting probes representing speech acts performed with the final remark. First, the participants made more errors when the probe represented a performed speech act $(9.42 \%)$ than when it did not $(5.44 \%)\left[F_{1}(1,45)=3.9, M S_{\mathrm{e}}=.06, p=\right.$ $\left..055 ; F_{2}(1,11)=5.09, M S_{\mathrm{e}}=.04\right]$. And second, the participants were again significantly slower at making this judgment when the probe represented a prior speech act $(M=1,099 \mathrm{msec})$ than when it $\operatorname{did} \operatorname{not}(M=1,047 \mathrm{msec})$. This effect was reliable over participants $\left[F_{1}(1,45)=6.2\right.$, $\left.M S_{\mathrm{e}}=45,536\right]$, although not over items $\left[F_{2}(1,11)=1.24\right.$, $\left.M S_{\mathrm{e}}=281,101, p<.30\right]$.

In Experiments 1 and 2, the reaction time differences were reliable over participants but not over items. To provide a more powerful test of this effect over items, the data from these two experiments were combined (thereby providing more stable reaction times for each stimuli). In this analysis, the reaction time difference was quite reliable over items $\left[F_{2}(1,11)=9.41, M S_{\mathrm{e}}=2,989\right]$, as was the error rate difference $\left[F_{2}(1,11)=11.86, M S_{\mathrm{e}}=.001\right]$.

Performance on the delayed recognition test was consistent with performance on the recognition probe reaction time task; the participants displayed significant memory for the speech acts performed with the remarks. 
Specifically, the participants were far more likely to indicate that the speech act words characterized remarks read earlier $(M=60 \%)$, relative to words that had not performed speech acts $(M=44 \%)$. This effect was reliable over participants $\left[F_{1}(1,45)=19.62, M S_{\mathrm{e}}=.031\right]$ and over items $\left[F_{2}(1,11)=9.81, M S_{\mathrm{e}}=.016\right]$.

\section{EXPERIMENT 3}

The purpose of this experiment was to obtain additional evidence regarding the activation of illocutionary force. It was possible that the reaction time results in Experiments 1 and 2 were due to some type of contextchecking procedure that occurred when the participants verified the probes. That is, reaction times might have been slowed for the speech act probes, not because these words had been activated during comprehension, but because when the judgments were made, the speech act probes were more plausible than the control words. Because of this plausibility (rather than any actual activation), the participants might have spent more time considering whether the probe had been presented. This possibility was less plausible as an explanation for the obtained differences in error rates and delayed recognition memory. Still, additional evidence would be desirable. This was the purpose of Experiment 3.

The stimulus materials were the same as those used Experiment 2. However, the experimental task was changed. Rather than verifying whether a word had been literally present in the preceding remark, the participants instead performed a lexical decision task (judge whether a presented letter string was a word). On critical trials, the target was always a word; one half of the time it was the speech act performed with the final remark, and one half of the time it was not. If comprehension of the utterance involved speech act activation, the participants should be significantly faster at this task when the target represented the performed speech act than when it did not. On the basis of the results of Experiments 1 and 2, we expected faster reaction times for the former than for the latter.

\section{Method}

Participants. The participants $(N=48)$ were students enrolled in introductory psychology classes at Ball State University who participated for partial course credit. All were native speakers of English.

Materials. The materials were the same as those used in Experiment 2, with one exception. For the 12 filler trials, the target was always a nonword. In this way, the targets for the 12 critical trials were always words (requiring "Yes" responses) and the targets for the 12 filler trials were always nonwords (requiring "No" responses).

Procedure. The procedure was identical to that used in Experiment 2, with the following exceptions. After the participants had indicated their comprehension of the final remark, the screen went blank for $250 \mathrm{msec}$, a $500-\mathrm{Hz}$ tone sounded for $50 \mathrm{msec}$, and the target then appeared in the middle of the screen. The participants were instructed to indicate, as quickly as possible, whether the presented target was a word. They pushed the key marked "Yes" (/ key) if the target was a word, and the key marked "No" (z key) if the target was not a word. The participants were given feedback after every trial. After they had completed this task, the participants then completed the modified recognition memory test used in Experiment 2.

\section{Results and Discussion}

Only error-free trials were included in the analyses. The overall error rate was $9.6 \%$, and this rate did not vary across conditions $\left[F_{1}(1,47)=1.38, M S_{\mathrm{e}}=.10 ; F_{2}(1,11)=\right.$ $1.94, M S_{\mathrm{e}}=.07$ ]. The results (see Table 3 ) were quite consistent with those of Experiments 1 and 2. As expected, the participants were significantly faster at the lexical decision task when the target represented the prior speech act $(M=1,002 \mathrm{msec})$ than when it did not $(M=1,095 \mathrm{msec})$. This effect was reliable over both participants $\left[F_{1}(1,47)=6.4, M S_{\mathrm{e}}=169,598\right]$ and items $\left[F_{2}(1,11)=8.01, M S_{\mathrm{e}}=137,758\right]$.

And again, performance on the delayed recognition memory test was consistent with performance on the online task. The participants were more likely to indicate that speech act words characterized the remarks that they had read earlier $(M=73 \%)$, relative to words that did not represent performed speech acts $(M=59 \%)\left[F_{1}(1,47)=\right.$ $\left.14.44, M S_{\mathrm{e}}=.034 ; F_{2}(1,11)=7.98, M S_{\mathrm{e}}=.015\right]$.

\section{EXPERIMENT 4}

A potential problem with Experiment 3 was that faster lexical decisions might have been due to the priming of semantic associates of words in the speech act sentences, rather than a result of participants' recognizing the speech act performed. Experiment 4 was conducted to control for this possibility. Experiment 4 was an exact replication of Experiment 3, but with the target sentences equated in terms of their semantic associates.

\section{Method}

Participants. The participants $(N=60)$ were students enrolled in introductory psychology classes at Ball State University who participated for partial course credit. All were native speakers of English. The data from 2 participants were excluded because of failure to follow instructions (and read the materials before making the lexical decision).

Materials and Procedure. The procedure was identical to that of Experiment 3. However, the control sentences were changed so as to be as similar to the speech act sentences as possible. In general, this was accomplished by using the speech act remark in the control condition, but by either changing its tense (past rather than present) or by changing the referent (the remark referred to someone other than the recipient of the remark).

\section{Results and Discussion}

Only error-free trials were included in the analyses. The overall error rate was $9 \%$, and this did not vary over conditions $\left[F_{1}(1,57)<1, M S_{\mathrm{e}}=.06 ; F_{2}(1,11)<1, M S_{\mathrm{e}}=\right.$ .09]. The judgment speed results are presented in Table 3 .

The results were quite consistent with those of Experiment 3 . As expected, the participants were significantly

Table 3

Lexical Decision Reaction Times (in Milliseconds): Experiments 3 and 4

\begin{tabular}{ccc}
\hline Experiment & Speech Act Sentences & Control Sentences \\
\hline 3 & 1,002 & 1,095 \\
4 & 887 & 999 \\
\hline
\end{tabular}


faster at the lexical decision task when the target represented the prior speech act $(M=887 \mathrm{msec})$ than when it did not $(M=999 \mathrm{msec})$. This effect was reliable over both participants $\left[F_{1}(1,57)=4.82, M S_{\mathrm{e}}=51,723\right]$ and items $\left[F_{2}(1,11)=5.31, M S_{\mathrm{e}}=50,513\right]$. And again, performance on the delayed recognition memory test was consistent with performance on the on-line task. The participants were more likely to indicate that speech act words characterized the remarks that they had read earlier $(M=58 \%)$, relative to words that did not represent performed speech acts $(M=47.7 \%)\left[F_{1}(1,57)=8.9\right.$, $\left.M S_{\mathrm{e}}=.035 ; F_{2}(1,11)=12.05, M S_{\mathrm{e}}=.0056\right]$.

\section{GENERAL DISCUSSION}

Speech act theory (Searle, 1969) has been an influential approach to language use; it represents one of the major lines of research in pragmatics and discourse analysis. Yet, apart from the exception of indirect speech acts, there has been relatively little empirical research on issues raised by this approach. Although speech act theory has been criticized in various ways (e.g., Cohen \& Levesque, 1990; Levinson, 1983), it does have the redeeming feature of providing the conceptual machinery for undertaking an analysis of language as social action. And in this way it allows for an empirical examination of the role of language as action in comprehension.

In general, our results support illocutionary force activation as an aspect of comprehension, at least for the speech acts that we examined. Specifically, when the participants in Experiments 1 and 2 read remarks performing a speech act, their ability (in terms of both speed and accuracy) to verify that a word naming that speech act had not been literally present in the remark was hindered. When the experimental task was changed to a lexical decision procedure (Experiments 3 and 4), the participants were faster at indicating that a letter string was a word when it represented the performed speech act than when it did not. This suggests that comprehension involved activation of the speech act word, and that this activation interfered with performance on the recognition probe task and facilitated performance with the lexical decision task. Finally, in Experiments 2-4 the participants demonstrated significant memory for the speech acts performed with the remarks that they had read. Thus, we have converging evidence from four separate experiments and three different methods that illocutionary force is activated.

Recognition of illocutionary force represents an inference of sorts, and it is difficult to assess unequivocally the extent to which inferences are made during comprehension. There are no completely unambiguous measures in this regard (see, e.g., Keenan, Golding, Potts, Jennings, \& Aman, 1990). Thus, there is the possibility that performance on the recognition probe task (Experiments 1 and 2) reflected some type of context checking procedure. But obtaining conceptually similar results in Experiments 3 and 4 argues against this possi- bility. Importantly, performance on the two on-line measures that we used (recognition probe reaction time and a lexical decision task) is differentially affected by speech act activation; speech act activation hinders performance on the recognition probe task but facilitates lexical decision performance. The consistency of our results over these different tasks provides relatively strong converging support for the operation of the hypothesized processes.

But what exactly is the nature of speech act recognition? Our results point to speech act recognition as the activation, to some degree, of discrete lexical items (i.e., speech act verbs). Thus, we view our data as indicating that it is the illocutionary force rather than illocutionary point (e.g., assertive, directive, etc.) that is activated. However, the information contained in a speech act verb can be substantial. It appears, for example, that the comprehension of some speech act verbs (explicit performatives and quasi-performatives) entails recognition of the felicity conditions underlying those verbs (Amrhein, 1992). Whether or not abstract knowledge of this sort plays a role in the comprehension of the implicit speech act verbs that we investigated is not clear.

Another potentially relevant aspect of speech act verbs is their perlocutionary effects. The perlocutionary dimension refers to the effect(s) that an utterance has on the intended recipient (Searle, 1969). For example, a request to perform some action may have the perlocutionary effect of the recipient's performing that action, or promising to do so. As with this example, many perlocutionary effects are systematically related to a specific illocutionary point. And there is some evidence that readers falsely recognize the perlocutionary effects of sentences that they have read earlier (Schweller et al., 1976), suggesting that the perlocutionary dimension may play some role in comprehension. It is not clear, however, whether such effects would occur on line. And it should be noted that unlike illocutionary force, perlocutionary effects are indeterminate. No single perlocutionary effect is alone associated with a remark; the range of reactions elicited by a remark is potentially infinite.

Although speech act theory has been very influential, there are alternative views of language use that take issue with the necessity of illocutionary force activation. For example, in Cohen and Levesque's (1990) treatment of intention in communication, people are viewed as rational agents possessing goals and plans designed to achieve those goals. People recognize each others' plans and goals, as well as possible obstacles to those goals, and act accordingly. Speech act recognition is not required, although it may be entailed in the recognition of the speaker's goals.

Similarly, according to a conversation-analytic perspective (e.g., Schegloff, 1991; see also Clark, 1996), an interactant's understanding of what has been accomplished with a remark is revealed in that person's subsequent turn at talk; there is no need to consider a dimension of illocutionary force. So, when Karen says "Sure, we'll come over for dinner tonight" in response to Ms. 
Ford's "Why don't you and your husband come over for dinner tonight?" Karen's turn reveals her understanding of the prior remark as an invitation. Although one's understanding of an utterance may be revealed in a subsequent turn at talk, there is no guarantee that it will. Thus, the issue of the comprehender's representation of the remark remains relevant, and our results demonstrate that some feature of a speaker's intention in uttering a remark may be a component of the comprehender's representation of that remark.

Text processing research has demonstrated the crucial role of inferential processing in the comprehension of texts. Yet none of the inferences that have been investigated in text processing research are similar to illocutionary force. This suggests that there may be important differences between processing narrative or expository texts and comprehending conversation remarks. Text writers may have a particular intention in writing a text (e.g., to convey a moral), but that intention will be realized over a stretch of discourse and not on a sentence-bysentence basis. Moreover, inferences regarding the author's intention do not appear to be generated on line (Graesser et al., 1994). Conversations, on the other hand, are interactive; people alternate between the speaker's and hearer's roles, and conversations cannot proceed (successfully) unless there is some understanding of what each speaker is attempting to accomplish with each utterance (Clark, 1996; Clark \& Wilkes-Gibbs, 1986). If my words "I will do it tonight" fail to elicit some recognition by my addressee that I am making a promise, I have not succeeded in doing what I set out to do. And if I fail in this way, a repair sequence can be initiated in order to correct the problem. In a conversation (as opposed to a text) there must be constant monitoring, on a turn-by-turn basis, of what each participant is up to.

In this regard, we do not mean to claim that every remark in a conversation performs a particular speech act. One reason for this is that many speech acts may be performed over a sequence of turns rather than with a single utterance (Levinson, 1983). For example, a request can be performed over a stretch of talk as interactants first check on relevant background conditions ("Are you busy right now?"; "No"; "Do you know anything about $\mathrm{x}$ ?"), and so on. Still, many conversational remarks (or short remark sequences) can be viewed as performing specific speech acts, and the comprehension of those utterances appears to involve some recognition of the speech act that is being performed.

Language use is a social activity that plays a role in many social processes, especially the processes involved in perceiving others. In much the same way that spontaneous trait inferences are made when people comprehend descriptions of behavior, speech act recognition appears to be a part of the comprehension of conversation remarks. And in both instances it is the act that is categorized rather than the actor (for spontaneous trait inferences) or the speaker (for speech act recognition). But there are times when spontaneous trait inferences also result in characterization of the actor (see, e.g., Overwalle, Drenth, \& Marsman, 1999; Whitney, Davis, \& Waring, 1994). And so it is possible that speech act recognition might sometimes result in inferences being made about the speaker. Utterances that are recognized as performing the acts of bragging, begging, and complaining might result in perceptions of the speaker as a braggart, beggar, and complainer. If and when speech act inferencing extends to speaker attributions of this sort remains to be seen.

\section{REFERENCES}

Amrhein, P. C. (1992). The comprehension of quasi-performative verbs in verbal commitments: New evidence for componential theories of lexical meaning. Journal of Memory \& Language, 31, 756-784.

Austin, J. L. (1962). How to do things with words. Oxford: Oxford University Press, Clarendon Press.

Bassili, J. N., \& SMith, M. C. (1986). On the spontaneity of trait attributions: Converging evidence for the role of cognitive strategy. Journal of Personality \& Social Psychology, 50, 239-246.

Clark, H. H. (1996). Using language. Cambridge: Cambridge University Press.

Clark, H. H., \& Wilkes-Gibbs, D. (1986). Referring as a collaborative process. Cognition, 22, 1-39.

Cohen, P. R., \& Levesque, H. J. (1990). Rational interaction as the basis for communication. In P. R. Cohen, J. Morgan, \& M. E. Pollack (Eds.), Intentions in communication (pp. 221-256). Cambridge, MA: MIT Press.

Dell, G., McKoon, G., \& Ratcliff, R. (1983). The activation of antecedent information during the processing of anaphoric reference in reading. Journal of Verbal Learning \& Verbal Behavior, 22, 121-132.

Dopkins, S., Klin, C., \& Myers, J. L. (1993). Accessibility of information about goals during the processing of narrative texts. Journal of Memory \& Language, 19, 70-80.

Gernsbacher, M. A., Goldsmith, H. H., \& Robertson, R. R. (1992). Do readers mentally represent characters' emotional states? Cognition \& Emotion, 6, 89-112.

GibBs, R. W. (1983). Do people always process the literal meaning of indirect requests? Journal of Experimental Psychology: Learning, Memory, \& Cognition, 9, 524-533.

Gibbs, R. W., \& Delaney, S. (1987). Pragmatic factors in making and understanding promises. Discourse Processes, 10, 107-126.

Graesser, A. C., Singer, M., \& Trabasso, T. (1994). Constructing inferences during narrative text comprehension. Psychological Review, 101, 371-395.

Higgins, E. T., \& BARgh, J. (1987). Social cognition and social perception. Annual Review of Psychology, 38, 369-425.

Keenan, J. M., Golding, J. M., Potts, G. R., Jennings, T. M., \& Aman, C. J. (1990). Methodological issues in evaluating the occurrence of inferences. In A. C. Graesser \& G. H. Bower (Eds.), Inferences and text comprehension (pp. 295-312). San Diego: Academic Press.

Levinson, S. (1983). Pragmatics. Cambridge: Cambridge University Press.

McKoon, G., \& Ratcliff, R. (1992). Inferences during reading. Psychological Review, 99, 440-466.

Overwalle,F., Drenth, T., \& Marsman, G. (1999). Spontaneous trait inferences: Are they linked to the actor or to the action? Personality \& Social Psychology Bulletin, 25, 450-462.

Schegloff, E. A. (1991). Conversational analysis and socially shared cognition. In L. B. Resnick, J. M. Levine, \& S. D. Teasley (Eds.), Perspectives on socially shared cognition (pp. 150-171). Washington, DC: American Psychological Association.

Schweller, K., Brewer, W., \& DAhl, D. (1976). Memory for illocutionary forces and perlocutionary effects of utterances. Journal of Verbal Learning \& Verbal Behavior, 15, 325-337. 
Searle, J. R. (1969). Speech acts. Cambridge: Cambridge University Press.

SeArle, J. R., \& VAnderveken, D. (1985). Foundations of illocutionary logic. Cambridge: Cambridge University Press.

Singer, M., Halldorson, M., Lear, J. C., \& Andrusiak, P. (1992). Validation of causal bridging inferences in discourse understanding. Journal of Memory \& Language, 31, 507-524.

SwinNey. D., \& Osterhout, L. (1990). Inference generation during auditory language comprehension. In A. C. Graesser \& G. H. Bower (Eds.), Inferences and text comprehension (pp. 17-33). San Diego: Academic Press.

Uleman, J. S. (1987). Consciousness and control: The case of spontaneous trait inferences. Personality \& Social Psychology Bulletin, 13, 337-354.

Uleman, J. S., Han, A., Roman, R. J., \& Moskowitz, G. B. (1996). On-line evidence for spontaneous trait inferences at encoding. Personality \& Social Psychology Bulletin, 22, 377-394.

Whitney, P., Davis, P. A., \& Waring, D. A. (1994). Task effects on trait inference: Distinguishing categorization from characterization. Social Cognition, 12, 19-35.
Whit ney, P., \& Williams-Whitney, D. L. (1990). Toward a contextualist view of elaborative inferences. In A. C. Graesser \& G. H. Bower (Eds.), Inferences and text comprehension (pp.279-293). San Diego: Academic Press.

Winter, L., \& Uleman, J. S. (1984). When are social judgments made? Evidence for the spontaneousness of trait inferences. Journal of Personality \& Social Psychology, 47, 237-252.

Winter, L., Uleman, J. S., \& CunnifF, C. (1985). How automatic are social judgments? Journal of Personality \& Social Psychology, 49, 904-917.

\section{NOTES}

1. All stimulus materials used in these experiments are available from the first author.

2. The effect is significant over items when the data from Experiments 1 and 2 are combined. See the Experiment 2 results.

(Manuscript received November 29, 1999; revision accepted for publication June 26, 2000.) 